\title{
Ethical issues cloud case report of unproven stem cell therapy for autism
}

\author{
BY PETER HESS
}

10 DECEMBER 2021

\section{Listen to this story:}

https://www.spectrumnews.org/wp-content/uploads/2021/12/audio-8c3ffc18-5c0c-4b3ab136-005559046e21-encodings.mp3

Undisclosed financial conflicts of interest and a lack of proper clearance mar a new study that injected four autistic children with stem cells from their own bone marrow, bioethicists say.

The study, which was published in October in Frontiers in Pediatrics, did not undergo ethical review and approval by an institutional review board (IRB), a critical step for research involving human participants.

"While I'm not familiar with their local or institutional regulations, in my view international standards would require prior institutional review and approval for this kind of experimental intervention," says Paul Knoepfler, professor of cell biology and human anatomy at the University of California, Davis, who has blogged critically about stem cell treatments for autism. "There's also no good rationale for the experimental treatment they used, which would have been something that an IRB also discussed," Knoepfler says.

What's more, the study investigators did not disclose their ties to an Austrian clinic that sells the unproven therapy, nor did they disclose that the four children's families paid to receive the injections - possible financial conflicts of interest. An unrelated 2019 study of an unproven stem cell therapy for autism was retracted last week after similarly failing to disclose that its participants had paid to receive the treatment.

The new study's lead investigator Georg Kobinia, director of the Austrian Society for Regenerative Medicine, does not dispute that the participants' families paid for his stem cell procedures. In response to emailed questions from Spectrum, Kobinia confirmed that the 


\section{Spectrum | Autism Research News}

https://www.spectrumnews.org

participants' families had paid to receive the injections, but he did not answer questions about how much the procedure cost.

The treatments were ethically justifiable, he told Spectrum, because they were performed only after other autism therapies had failed to produce changes in the children's behavior and co-occurring physical conditions.

Still, the largest placebo-controlled clinical trial of a stem cell treatment for autism to date showed no meaningful benefits, which raises questions about the rationale for Kobinia's team's approach.

The children in the new study, who ranged from 3 to 14 years old, received the stem cell injections at Kobinia's medical office, Stem Cell Therapy-Vienna, in Austria. While the children were sedated, Kobinia and his team extracted bone marrow from each child's hip bone, separated out the stem cells and then administered them back to each child via both a spinal tap and an intravenous infusion.

Before the treatment and at three-month intervals during the following year, the researchers asked the children's parents to fill out the Autism Treatment Evaluation Checklist, a questionnaire that asks about changes in a child's autism-related behaviors. None of the children's parents reported outcomes at all five time points.

All four children's scores decreased after treatment, suggesting a reduction in autism traits and the severity of co-occurring physical issues. For instance, parents of one child reported improvement in their son's digestive issues, which autistic people experience at higher rates than their nonautistic peers do.

The team describes its work as "promising." But the case series does not compare the four treated children with placebo or treatment-as-usual controls, so it is not clear how they can say that or draw any firm conclusions, Knoepfler says. "There's still a long way to go before the field gets to the point where people are convinced that this is an effective treatment."

What's more, parent-reported outcomes can be unreliable, introducing several types of bias into a study, says Kristen Bottema-Beutel, associate professor of teaching, curriculum and society at Boston College in Massachusetts. Parents are invested in seeing their child gain from an intervention and may change the way they interact with their child, which can lead to positive changes - a form of bias called placebo-by-proxy, she says. And parents so want their children to benefit from an intervention that, even in the absence of real improvements, they can subconsciously provide higher ratings on post-intervention reports, an issue known as detection bias. Bottema-Beutel studies conflicts of interest in autism research and is sometimes paid to speak on the topic. 


\section{Spectrum | Autism Research News}

https://www.spectrumnews.org

Kobinia says that the stem cell injection he and his colleagues used does not constitute an 'experimental therapy' and therefore does not require approval by an IRB. He also says that the retrospective nature of the case report precludes these procedures being classified as trials.

But for the case series to be retrospective, the children would have had to receive the stem cells with ethical approval - for a different condition, Knoepfler says. Then, Kobinia and his team would have had to dig into the data after the fact to find out whether the procedure had inadvertently improved their autism-related behavioral traits.

"Otherwise, anyone could do human experiments without IRB approval and then just claim that since reporting about it in a manuscript came later, that no IRB approval was needed," he says.

Additionally, despite conducting the treatments in a medical office that sells stem cell therapies for various conditions, and even though families paid for the procedure, Kobinia and his colleagues reported in their study that "the research was conducted in the absence of any commercial or financial relationships that could be construed as a potential conflict of interest." In response to Spectrum's questions about this, Kobinia says there was no conflict, as a doctor's office is not a company or clinic.

But the conflict-of-interest issue "is not addressed by claiming a doctor's office location," says Arthur Caplan, director of medical ethics at New York University in New York City. "That is laughable."

\section{Cite this article: https://doi.org/10.53053/ARWI8127}

